\title{
Meteorological Influence on Ambient PAH in Abetifi, Ghana
}

\author{
Linda M.D Palm ${ }^{1,2}$, Samuel B. Dampare ${ }^{2}$, Sarah Blankson-Arthur ${ }^{1}$, Sam Adu-Kumi ${ }^{3}$, Innocent J.Y.Aboh ${ }^{2}$ \\ ${ }^{1}$ Nuclear Chemistry and Environmental Research Centre, Ghana Atomic Energy Commission \\ P.O. Box LG 80, Legon, Accra, Ghana \\ l.mnpalm@gaecgh.org; sbdampare@ug.edu.gh \\ ${ }^{2}$ School of Nuclear and Allied Sciences, College of Basic and Applied Sciences \\ University of Ghana. P.O. Box AE 1, Atomic-Accra, Ghana \\ ${ }^{3}$ Chemicals Control and Management Centre, Environmental Protection Agency \\ P.O. Box MB 326, Accra, Ghana
}

\begin{abstract}
Polycyclic Aromatic Hydrocarbons (PAHs) are ubiquitous environmental pollutants whose concentration in the environment are subject to various environmental factors. In this study, the effect of meteorology (wind speed, temperature and solar hours) on levels of ambient PAH from a mountainous environment, Abetifi in Ghana was evaluated. Samples were collected every 28days for a period of two-years by employing passive air sampling (PAS) method with polyurethane foam (PUF) as adsorbent. Mean concentrations of the PAH ( $\left.\Sigma_{16} \mathrm{PAHs}\right)$ recorded in ambient air at Abetifi ranged from below limit of quantification to $8.434 \mathrm{ng} / \mathrm{m}^{3} \mathrm{with}$ the most abundant PAH identified to be naphthalene followed by phenantrene and fluoranthene. Positive relationship exists between PAH levels and some meteorological factors. Moderately significant seasonal variations exist. Influence on total $\Sigma_{16}$ PAH concentration showed wind speed (36\%), temperature (32\%), humidity (27\%) and solar hours $(23 \%)$. The effect of rainfall pattern revealed an influence of precipitation scavenging. Solar hours showed $11 \%$ influence on photo-oxidation.
\end{abstract}

Keywords: Polycyclic aromatic hydrocarbons, Abetifi, Influence, Rainfall, Solar hours, Wind speed, PUF.

\section{Introduction}

In recent times global attention has been turned to air pollution. This is most probably because once emitted, the control of the atmospheric pollutants are exceedingly challenging perhaps virtually impossible. Particular interest is the group of polycyclic aromatic hydrocarbons (PAHs) which has inherent toxicity to humans $[1,2]$ and the environment $[3$, 4]. PAHs are formed as by-products of combustion, mainly as a result of incomplete combustion or pyrolysis of organic material [5]. PAHs are semi-volatile and are released mostly from anthropogenic activities [3] particularly from wood burning for domestic uses, refuse burning and automobile exhaust $[6,7]$. PAHs are well-known to form high levels of DNA adducts, causing mutations, reproductive defects, and cancers in various tissues [8,9].

In the atmosphere, PAHs are characterized by long range transport and so are found even in remote ecosystems such as the high Arctic as well as far over the Pacific Ocean [10]. Consequently, many Scientists are putting in frantic efforts including using various techniques and methods to provide data on PAH pollution status in the environment $[4,11,12,13$, 14, 15]. High mountains and mountainous environments are one such environment which have been identified to act as convergence zone for semi-volatile organic pollutants $[16,17,18]$ and so must be continually monitored. Having identified the atmosphere as a suitable medium for estimating the spatial distribution and temporal changes in concentrations of such PAHs [16, 19] in such an environment, the level of atmospheric PAHs from one of the highest altitude forest environments in Ghana was assessed with regards the effect of meteorology on the spatial and temporal variations. By this work, data generated will help in achieving the United Nation's millennium and sustainable development goals; environmental sustainability, good health and well-being, sustainable cities and communities and climate action.

\section{Experimental Materials and Methods 2.1. Sampling site}


Passive air samplers (PAS) were deployed at Abetifi meteorological station, Eastern Region of Ghana (Fig. 1). Abetifi is located on longitude $0.45^{\circ} \mathrm{W}$ and latitude $6.41^{\circ} \mathrm{N}$. A highland $(594.7 \mathrm{~m}$ above sea level) tropical rainforest with a mean annual temperature of $25.2^{\circ} \mathrm{C}$, mean annual precipitation of $1463.85 \mathrm{~mm}$ and $84 \mathrm{~h}$ of solar hours per year.

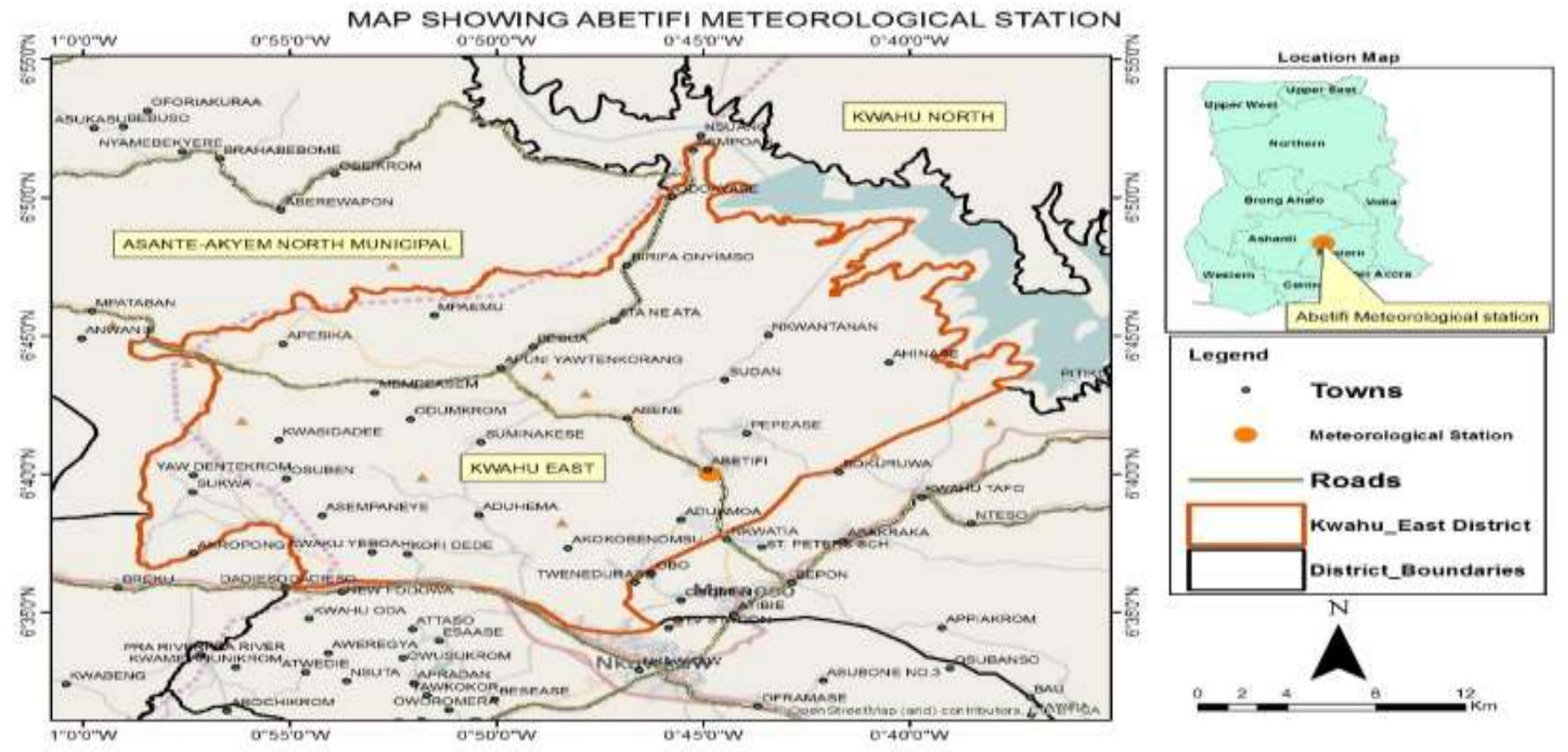

Fig. 1: Sampling area, Abetifi in the Eastern Region of Ghana.

\subsection{Air sampling}

Samples were collected every 28-days for 24 consecutive times. Two PUF-disks samples were mounted in each sapling campaign. PAS-PUF disk with specifications; $0.030 \mathrm{~g} / \mathrm{cm}^{3}, 15 \mathrm{~cm}$ diameter and $1.5 \mathrm{~cm}$ thickness was used for the sampling. The PUF disks were confined in stainless steel domed chambers, designed to protect the disks from coarse particle deposition, precipitation and sunlight [20]. Prior to the sampler installation, sampling domed chambers were washed and rinsed first with water then with acetone. The PUF disks were also conditioned by first pre-cleaning $8 \mathrm{~h}$ in each solvent (acetone and dichloromethane) consecutively using Soxhlet extraction. They were then dried overnight in a heated fume chamber and wrapped in double-layered aluminium foil and placed in zip-lock polyethylene bags and removing excess air. The cleaned PUFs were kept in a freezer prior to deployment. After each sampling duration, exposed PUF disks were wrapped in double-layered pre-cleaned aluminium foil, labelled and placed into zip-lock polyethylene bags. Samples were conveyed to the laboratory in a cool box at $5{ }^{\circ} \mathrm{C}$ and stored at $-18{ }^{\circ} \mathrm{C}$ in the freezer until analysis. PUF disks were installed and removed same day during all sampling campaigns to obtain field blanks.

\subsection{Meteorological Parameters}

Meteorological information was recorded during the whole period of sample collection using the professional service of the Ghana Meteorological Agency. Wind speed and temperature were monitored continuously at $2 \mathrm{~m}$ above the ground using an automatic weather station (Vaisala HydroMet, Finland). Mean values were calculated for the 28-day period during which the PUF disks were deployed (Table 1).

\section{Results and discussion 3.1. Concentration of ambient PAH}


Concentrations of PAH ( $\left.\Sigma_{16} \mathrm{PAHs}\right)$ recorded in ambient air at Abetifi are summarized in Table 2 with mean concentrations ranging from below limit of quantification to $8.434 \mathrm{ng} / \mathrm{m}^{3}$. In this study gas phase PAHs were generally higher than the particulate ones. This is in conformity to general observation that vapour-phase PAHs are higher than the particulate ones in tropical regions [2, 21, 22]. This observation is also expected as [11] has estimated particulate-phase sampling rate as approximately $10 \%$ of the vapour-phase based on the sampling method employed in this work. In the study, ACE and DBahA were found to be below the limit of quantification throughout the study. BghiP and IcdP were also detected just once throughout the study period. The most abundant PAH in the study was identified to be NAPH followed by PHEN and FLT.

Table 1: Sampling period and conditions prevailing at Abetifi, Ghana.

\begin{tabular}{rlccccccc}
\hline SC no. & ID & St Date & Tm Date & Temp. & WD & Hum. & Prec. & S Hrs \\
\hline 1 & ABm1 & $01 / 01 / 2010$ & $01 / 02 / 2010$ & 26.3 & NE & 81 & 41.4 & 7.8 \\
2 & ABm2 & $01 / 02 / 2010$ & $01 / 03 / 2010$ & 27.3 & SW & 78 & 59 & 8.4 \\
3 & ABm3 & $01 / 03 / 2010$ & $06 / 04 / 2010$ & 26.7 & SW & 78 & 144.1 & 6.4 \\
4 & ABm4 & $06 / 04 / 2010$ & $26 / 04 / 2010$ & 26.5 & SW & 80 & 115.7 & 7.5 \\
5 & ABm5 & $26 / 04 / 2010$ & $24 / 05 / 2010$ & 25.9 & SW & 81 & 140.4 & 7.5 \\
6 & ABm6 & $24 / 05 / 2010$ & $21 / 06 / 2010$ & 24.7 & SW & 87 & 105.8 & 5.9 \\
7 & ABm7 & $21 / 06 / 2010$ & $19 / 07 / 2010$ & 23.5 & SW & 88 & 108.5 & 6.4 \\
8 & ABm8 & $19 / 07 / 2010$ & $16 / 08 / 2010$ & 23.5 & SW & 93 & 89 & 4.8 \\
9 & ABm9 & $16 / 08 / 2010$ & $13 / 09 / 2010$ & 23.7 & SW & 90 & 295.1 & 4.7 \\
10 & ABm10 & $13 / 09 / 2010$ & $11 / 10 / 2010$ & 24.5 & SW & 84 & 359 & 6.2 \\
11 & ABm11 & $11 / 10 / 2010$ & $08 / 11 / 2010$ & 25 & SW & 80 & 101.7 & 7.8 \\
12 & ABm12 & $08 / 11 / 2010$ & $06 / 12 / 2010$ & 25.4 & NE & 77 & 67.6 & 9.1 \\
13 & ABm13 & $06 / 12 / 2010$ & $03 / 01 / 2011$ & 25.8 & NE & 59 & 0 & 7.3 \\
14 & ABm14 & $03 / 01 / 2011$ & $31 / 01 / 2011$ & 26.2 & NE & 70 & 106.1 & 7.8 \\
15 & ABm15 & $31 / 01 / 2011$ & $28 / 02 / 2011$ & 26.1 & SW & & 79.5 & 7.9 \\
16 & ABm16 & $28 / 02 / 2011$ & $28 / 03 / 2011$ & 26.4 & SW & & 109.2 & 8 \\
17 & ABm17 & $28 / 03 / 2011$ & $25 / 04 / 2011$ & 25.6 & SW & & 98.5 & 6.9 \\
18 & ABm18 & $25 / 04 / 2011$ & $23 / 05 / 2011$ & 24.6 & SW & & 198 & 6.2 \\
19 & ABm19 & $23 / 05 / 2011$ & $20 / 06 / 2011$ & 23.3 & SW & & 203.8 & 5.6 \\
20 & ABm20 & $20 / 06 / 2011$ & $18 / 07 / 2011$ & 23.2 & SW & 92 & 17.9 & 4.7 \\
21 & ABm21 & $18 / 07 / 2011$ & $15 / 08 / 2011$ & 24.1 & SW & 89 & 198 & 4.9 \\
22 & ABm22 & $15 / 08 / 2011$ & $12 / 09 / 2011$ & 24.3 & SW & 83 & 286.8 & 6.2 \\
23 & ABm23 & $12 / 09 / 2011$ & $10 / 10 / 2011$ & 25.6 & SW & 78 & 2.6 & 9.7 \\
24 & ABm24 & $10 / 10 / 2011$ & $07 / 11 / 2011$ & 25.8 & NE & 68 & 0 & 8.8 \\
\hline
\end{tabular}

$\mathrm{ID}=$ Sample ID, St Date=Start date, Tm Date=Termination date, Temp.=Mean Temperature, WD-Prevailing wind direction, Hum. $=$ Humidity, Prec. $=$ Precipitation, $\mathrm{S}$ Hrs=Solar hours.

Table 2: Ambient PAH concentrations found in Abetifi, Ghana.

\begin{tabular}{llllllc}
\hline PAH & Abbrev & $\begin{array}{l}\text { Total } \\
\text { Annual Conc. }\end{array}$ & $\begin{array}{l}\text { Minimum } \\
\text { Conc. }\end{array}$ & $\begin{array}{l}\text { Maximum } \\
\text { Conc. }\end{array}$ & $\begin{array}{l}\text { Mean Monthly } \\
\text { Conc. } \pm \text { std.error }\end{array}$ \\
\hline Naphthalene & NAPH & 109.637 & 1.902 & 20.869 & 8.434 & \pm 1.648 \\
Acenaphtylene & ACEN & 1.111 & 0.014 & 0.142 & 0.085 & \pm 0.013 \\
Acenaphtene & ACE & BLQ & BLQ & BLQ & BLQ & - \\
Fluorene & FLU & 7.06 & 0.279 & 0.75 & 0.543 & \pm 0.038
\end{tabular}




\begin{tabular}{lllllll} 
Phenantrene & PHEN & 45.574 & 2.06 & 4.554 & 3.506 & \pm 0.184 \\
Anthracene & ANT & 4.129 & 0.00 & 0.524 & 0.318 & \pm 0.041 \\
Fluoranthene & FLT & 31.918 & 1.289 & 3.566 & 2.455 & \pm 0.15 \\
Pyrene & PYR & 23.944 & 0.866 & 2.475 & 1.842 & \pm 0.113 \\
Benzo(a)anthracene & BaA & 3.018 & 0.099 & 0.315 & 0.232 & \pm 0.016 \\
Chrysene & CHRY & 4.836 & 0.193 & 0.623 & 0.372 & \pm 0.028 \\
Benzo(b)fluoranthene & BbF & 1.444 & 0.059 & 0.213 & 0.111 & \pm 0.011 \\
Benzo(k)fluoranthene & BkF & 0.485 & 0.023 & 0.063 & 0.037 & \pm 0.003 \\
Benzo(a)pyrene & BaP & 0.329 & 0.009 & 0.038 & 0.025 & \pm 0.002 \\
Indeno(123cd)pyrene & IcdP & 0.03 & 0.00 & 0.03 & - & - \\
Dibenz(ah)anthracene & DBahA & BLQ & BLQ & BLQ & BLQ & - \\
Benzo(ghi)perylene & BghiP & 0.024 & 0.00 & 0.024 & - & - \\
\hline \multicolumn{7}{c}{ BLQ - Below limit of quantification } \\
\hline
\end{tabular}

\subsection{Effects of meteorological parameters}

Table 3 shows the results of correlation analysis between $\Sigma_{16} \mathrm{PAHs}$ and meteorological parameters. The table revealed a moderate positive correlation for solar hours, temperature and wind speed of which wind speed was the highest. A negative association however was observed of rainfall and $\Sigma_{16} \mathrm{PAHs}$.

\subsubsection{Rainfall}

A negatively weak correlation observed for $\Sigma_{16} \mathrm{PAHs}$ and rainfall $(\mathrm{r}=-0.10)$, an indication that the higher the rainfall, the lower $\Sigma_{16} \mathrm{PAH}$ concentration in the atmosphere at Abetifi. This effect of rainfall on atmospheric PAH concentrations is an implication of precipitation scavenging which is a removal mechanism of atmospheric aerosol [23]. Work done by [24] in Delhi also recorded a negative correlation $(r=-0.29)$ between rainfall pattern and PAH concentration.

Table 3: Pearson correlation matrix between PAHs and meteorological parameters.

\begin{tabular}{|c|c|c|c|c|c|c|c|c|c|}
\hline & $\begin{array}{l}\text { wind } \\
\text { speed }\end{array}$ & Sun hrs & Rainfall & Temperature & Humidity & $\mathrm{BaP}$ & $\begin{array}{c}\mathrm{BaP} \\
\text { Ratio* }\end{array}$ & $\begin{array}{l}\text { Vap } \\
\text { PAH }\end{array}$ & $\Sigma_{16} \mathrm{PAH}$ \\
\hline wind speed & 1 & & & & & & & & \\
\hline Sun hrs & -0.262 & 1 & & & & & & & \\
\hline Rainfall & -0.081 & -0.531 & 1 & & & & & & \\
\hline Temperature & 0.117 & 0.741 & -0.386 & 1 & & & & & \\
\hline Humidity & -0.118 & -0.138 & 0.003 & -0.143 & 1 & & & & \\
\hline $\mathrm{BaP}$ & -0.212 & 0.083 & 0.181 & -0.161 & 0.152 & 1 & & & \\
\hline BaP Ratio* & -0.346 & 0.118 & 0.152 & -0.205 & 0.233 & 0.887 & 1 & & \\
\hline Vap PAH & 0.357 & 0.229 & -0.106 & 0.307 & 0.274 & -0.221 & -0.170 & 1 & \\
\hline$\Sigma_{16} \mathrm{PAH}$ & 0.388 & 0.233 & -0.103 & 0.315 & 0.253 & -0.202 & -0.185 & 0.996 & 1 \\
\hline
\end{tabular}

\subsubsection{Wind speed}

The positive correlation between wind speed and PAH is indicative of the fact that higher wind speeds are associated with higher PAH concentrations in the atmosphere at Abetifi. This influence of wind speed on atmospheric $\mathrm{PAH}$ concentrations was evaluated further using the equation, $\log [\mathrm{PAH}]\left(\mathrm{ngm}^{-3}\right)=\mathrm{m} /$ wind speed $\left(\mathrm{knot}^{-1}\right)+\mathrm{C}$, where $\mathrm{m}$ is gradient and $\mathrm{C}$ is the intercept obtained after performing a linear regression [25]. The plot for the measured data $(\mathrm{Log}[\mathrm{PAH}]$ versus $1 /$ wind speed) (Fig. 2) gave a significant negative gradient $(\mathrm{m}=-0.09)$ and revealed that $11 \%$ change in the PAH concentration is due changes in the prevailing wind speed which was significant $(p=0.006)$. 
Two separate bands of wind speed were observed to prevail during the sampling campaign at Abetifi (Fig. 2). One band was less than 0.35 knot $(0.31-0.33 \mathrm{knot})$ and the other, greater than 0.35 knot $(0.40-0.53$ knots $)$. It has been postulated that uptake rate of PUF-disk will significantly depend on wind speed when the wind speed is between $>4$ and $5 \mathrm{~ms}^{-1}$ (approx. $7.78-9.73$ knot) [26]. In this work however the prevailing wind speed at Abetifi was far less than 7.78 knot hence the concentration which may be based on uptake rate observed in this work was minimal.

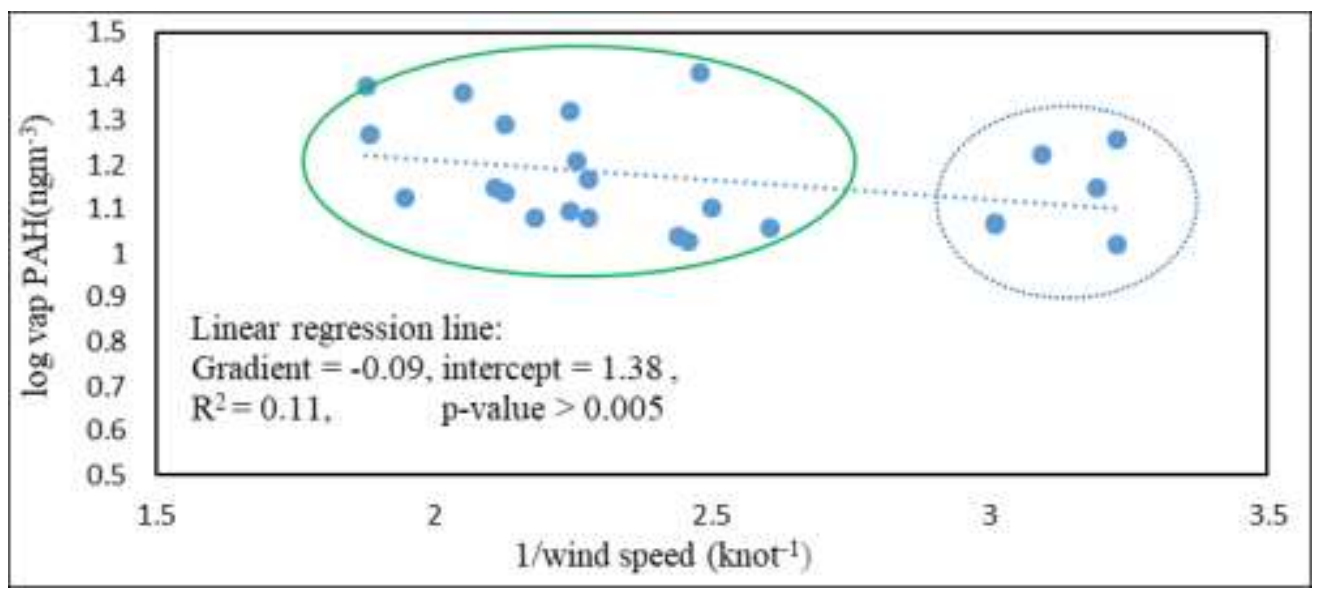

Fig. 2: The log PAH concentration as a function of inverse wind speed.

\subsubsection{Temperature}

Another meteorological parameter explored in this work with moderate positive correlation was temperature which reveal higher PAH concentrations with increase in temperature. Increasing seasonal trend corresponding with increasing temperature was demonstrated in [10] with a trend wide range of seasonal temperature ranges $\left(2.7^{\circ} \mathrm{C}-17.9{ }^{\circ} \mathrm{C}\right)$. In this work however, the temperature variation was very close $\left(23.2\right.$ to $\left.27.3{ }^{\circ} \mathrm{C}\right)$ and so can be assumed that its influence would be insignificant on spatial variations [3]. Nonetheless the PAH concentrations were further investigated by converting the measured data into the logarithmic form (log vap PAH) and regressed against reciprocal mean temperature $(1 / \mathrm{T})\left({ }^{\circ} \mathrm{C}^{-1}\right)$ of each sampling campaign. This was then plotted for the measured data (Fig. 3) and the plot gave a negative gradient $(\mathrm{m}=-$ 17.1), which revealed that every unit change in temperature was associated with $0.77 \mathrm{ngm}^{-3}$ of change in the PAH concentration $\left(\mathrm{R}^{2}=0.077\right)$ but this change was not significant $(p>0.005)$.

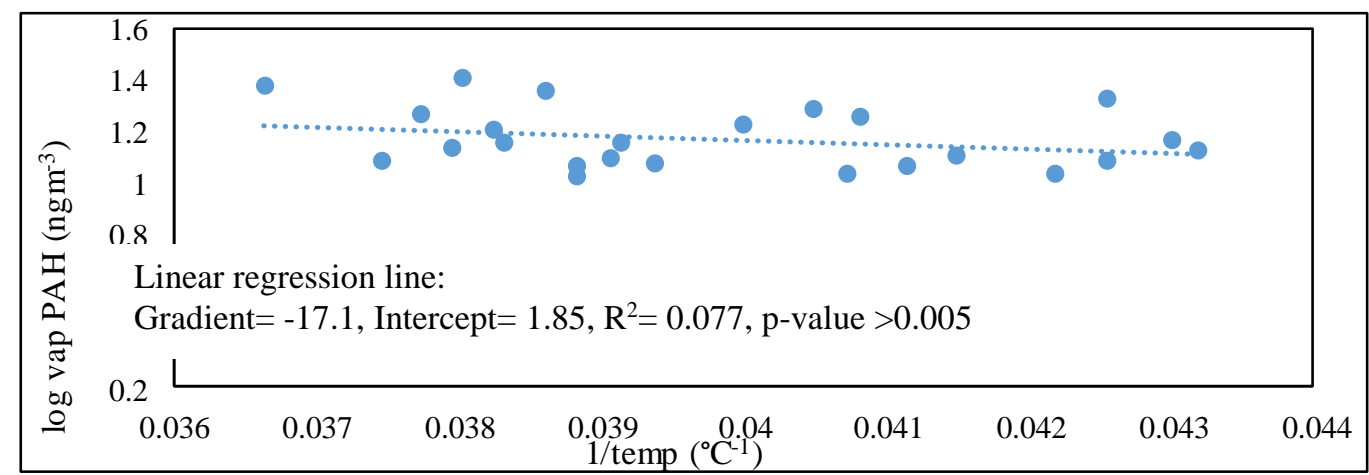

Fig. 3: The $\log$ PAH concentration as a function of inverse mean temperature. 


\subsubsection{Solar hours}

The average daily solar hours that prevailed during the sampling campaign in this work was 6.9 hours. The highest solar hours was observed was in November 2011 with 9.7 hours of sunshine followed by what was observed in December 2010 with 9.1 solar hours. In the study, positively moderate correlation $(23 \%)$ was observed between the PAH concentration and solar hours. Similar to fig. 3, a plot of the logarithmic PAH concentrations (log vap PAH) regressed against reciprocal solar hours $(1 /$ sun $\mathrm{Hrs})\left(\mathrm{Hrs}^{-1}\right)$ for each sampling period was done. The plot gave a negative gradient $(\mathrm{m}=-1.02)$ and revealed $8 \%$ contributing from solar hours to concentration changes in PAH which was not significant $(r=0.28, p>0.005)$.

\subsubsection{Photo-oxidation of PAHs}

In the presence of sunlight, PAHs undergo photo oxidation [27] by the absorption of the light and this reaction occurs much faster for vapour-phase PAHs than particle-phase ones [2]. Literature data suggest that photoreactions may strongly affect the ratio ANT/(ANT + PHEN) giving rise to ratios close to 0 [28]. ANT and PHEN are vapour-phase $\mathrm{PAHs}$ as such they fit for examining the effect of photo-oxidation in the vapour phase [29]. BaP and its isomer BeP are both photosensitive also. Their ratio, $\mathrm{BaP} /(\mathrm{BaP}+\mathrm{BeP})$ is also used to investigate the effect of photolysis on particlephase PAHs [30] and are often used as markers of atmospheric particle ageing and photo degradation of PAHs [28]. BeP was not detected in this work so a more atmospherically stable $\mathrm{PAH}$ species $\mathrm{BbF}$, [25] was selected i.e. $\mathrm{BaP} /(\mathrm{BaP}+$ $\mathrm{BbF})$.

The effect of photo-oxidation on the variation of the PAH levels was investigated using the ratio [Ant/(Ant+Phen)] (Fig. 4) and relative benzo[a]pyrene $(\mathrm{BaP})$ ratio $[\mathrm{BaP} /(\mathrm{BaP}+\mathrm{BbF})]$. Both $\mathrm{ANT}$ and $\mathrm{BaP}$ photo-degrade faster than their isomers [31]. The correlation analysis performed between solar hours prevailing at the time of sampling and [Ant/(Ant+Phen)] ratio gave a negative relationship (slope $=-18.0, \mathrm{R}^{2}=0.11$ ). This indicates higher solar hours for lower [Ant/(Ant+Phen)] ratios (ratios close to zero) which is suggestive of higher solar hours giving rise to stronger influence of photoreactions (photo-oxidation) on ANT with $11 \%$ sunlight influence. The [Ant/(Ant+Phen)] ratio were between 0 and 0.11, an indication of strong photo-degradation of vapour-phase PAHs. This result is in conformity to [32], whose long term study (1991 to 2008), identified [Ant/(Ant+Phen)] as the most seasonal PAH ratio with ratios between $0-0.13$ for data from London and $0.02-0.12$ for Glasglow.

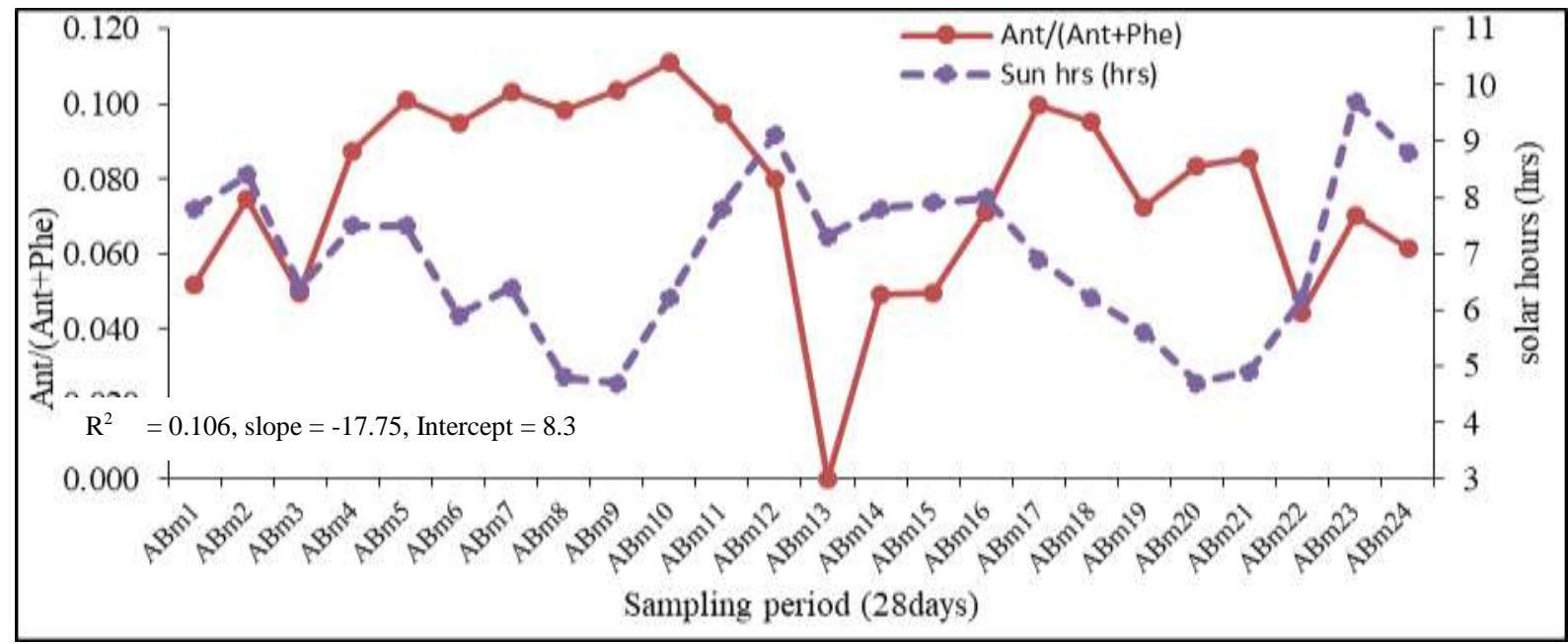

Fig. 4: Variations of [Ant/(Ant+Phen)] and solar hours during the sampling periods.

The relative benzo[a]pyrene $(\mathrm{BaP})$ ratio i.e. $[\mathrm{BaP} /(\mathrm{BaP}+\mathrm{BbF})]$ was also investigated for photo-degradation and particle ageing for PAHs in this study. The correlation between prevailing sun hours and relative BaP ratio showed a 
positive relationship (slope $=0.01, \mathrm{R}^{2}=0.01$ ) contrary to $[\mathrm{Ant} /(\mathrm{Ant}+\mathrm{Phen})]$ ratio (Figure 4$)$. The influence of sun hours on the particulate PAHs was very minimal $(1 \%)$.

\subsubsection{PAHs source identification}

Principal component analysis (PCA) was employed in this study to explore the extent of air pollution and to aid in their source identification. In the PCA, VARIMAX rotation with Kaiser Normalization was used to maximize the sum of the variance of the factor coefficients.

Table 4: VARIMAX rotated factor loading for PAH.

\begin{tabular}{lrrrr}
\hline & Factor & \multicolumn{1}{l}{ Factor } & \multicolumn{1}{l}{ Factor } & \\
& \multicolumn{1}{c}{1} & \multicolumn{1}{l}{ Communality } \\
\hline NAPH & -0.51 & 0.145 & -0.471 & 0.503 \\
ACEN & -0.214 & $\mathbf{0 . 8 8}$ & -0.214 & 0.867 \\
ACE & 0.569 & -0.029 & 0.382 & 0.471 \\
FLU & -0.403 & $\mathbf{0 . 7 4 9}$ & 0.277 & 0.801 \\
PHEN & $\mathbf{0 . 7 4 4}$ & 0.383 & 0.425 & 0.881 \\
ANT & 0.201 & $\mathbf{0 . 9 0 1}$ & -0.086 & 0.859 \\
FLT & $\mathbf{0 . 9 5 4}$ & -0.073 & 0.186 & 0.951 \\
PYR & $\mathbf{0 . 9 7 8}$ & 0.035 & 0.127 & 0.973 \\
BaA & $\mathbf{0 . 9 2 7}$ & 0.244 & -0.202 & 0.959 \\
CHRY & $\mathbf{0 . 9 6 8}$ & -0.154 & 0.063 & 0.965 \\
BbF & $\mathbf{0 . 9 2 8}$ & -0.123 & 0.105 & 0.886 \\
BkF & $\mathbf{0 . 8 9 5}$ & -0.208 & 0.303 & 0.936 \\
BaP & 0.078 & -0.044 & $\mathbf{0 . 8 9 9}$ & 0.815 \\
IcdP & $\mathbf{0 . 9}$ & -0.376 & 0.145 & 0.973 \\
BghiP & $\mathbf{0 . 8 1 2}$ & -0.307 & 0.156 & 0.778 \\
Variance explained by & each & & \\
factor & & & & 12.62 \\
& 8.19 & 2.7 & 1.73 & \\
\%variance & 54.6 & 18 & 11.5 & \\
\hline
\end{tabular}

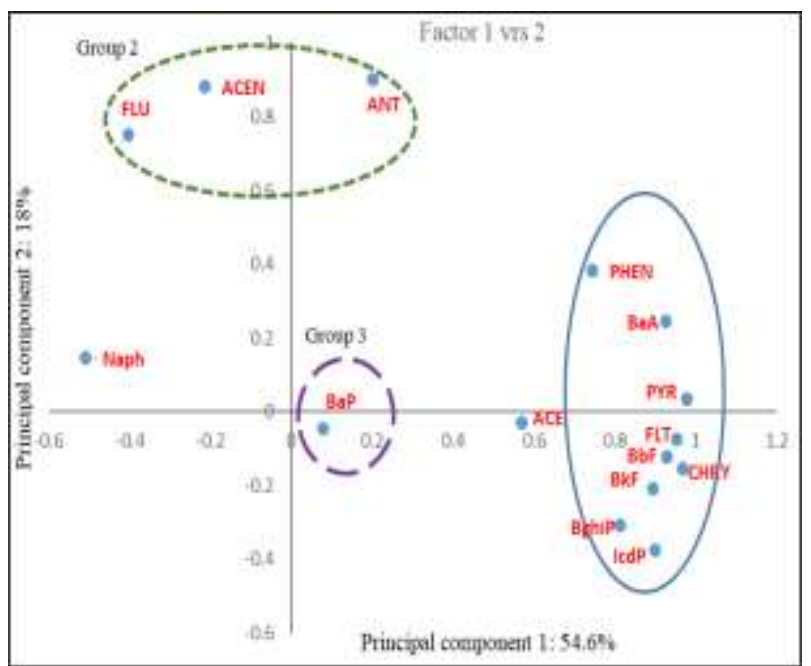

Fig. 5: PCA scores plot of the first two principal components of atmospheric PAHs in Abetifi.

Factor scores represent cumulate contribution of the PAH species loaded on a particular factor/principal component. Positive scores in the PCA are discloses of significant load from the presence of such PAH species on air quality. In the analysis, three factors with Eigen values $>1$ were extracted. The first principal component is plotted against the second principal component (Figure 5).

From the analysis (Table 4), the first principal component in the data set explains more than 54\% of total variance and is loaded with medium and high molecular weight PAHs including PHEN, FLT, PYR, BaA, CHRY, BbF, BkF, IcdP, BghiP, these are all identified as vehicular emission markers [33, 34, 35] Factor 1 is therefore vehicular emission source.

PC2 which explains 18\% of total variance has high loadings for ACEN, FLU and ANT which are all 3-membered ring PAHs. According to [28], during low temperature pyrogenic processes (such as biomass combustion of straw and firewood) low molecular weight PAHs are usually formed. This group is therefore indicative of biomass combustion. This is expected in that biomass combustion of straw and firewood, municipal wastes was a common practice in the study area.

PC 3 accounted for $11.5 \%$ of total variance and is exclusively loaded on BaP. Regarding the emissions of BaP as a sole source, other diagnostic ratios are required to confirm that.

\section{Conclusion}

In this study, I6 PAHs were in quantifiable measures with individual concentrations of up to $8.434 \mathrm{ng} / \mathrm{m}^{3}$. Meteorological factors affecting the levels of atmospheric PAHs in Abetifi were chiefly wind speed and temperature. The 
meteorological influence on total $\Sigma_{16} \mathrm{PAH}$ concentration showed wind speed (36\%), temperature (32\%), humidity (27\%) and solar hours (23\%). Every unit change in wind speed was associated with $1 \mathrm{ngm}^{-3}$ increase in total PAH level in the air. This study revealed that precipitation scavenging of PAHs occur at Abetifi anytime there is high rainfall and solar hours also showed $11 \%$ influence on PAH photo-oxidation. Two main PAH pollution sources were identified from this study; vehicular emission and biomass combustion.

\section{Acknowledgements}

The authors of this research wish to appreciate the immense support from the Secretariat in charge of the Global Monitoring Plan of the Stockholm Convention, the Scientists and Technologists at the Research Centre for Environmental Chemistry and Ecotoxicology, Masaryk University, Czech Republic and the Nuclear Chemistry and Environmental Research Centre of the Ghana Atomic Energy Commission. The assistance from the office of Research Innovation and Development, University of Ghana, the Ghana Meteorological Agency and the Queen Elizabeth Scholarship-Advanced Scholars project are all highly appreciated.

\section{References}

[1] UNEP Stockholm Convention on Persistent Organic Pollutants (2002). [Online]. Available: http://chm.pops.int/

[2] H. I. Abdel-Shafy and M. S. M. Mansour, "A review on polycyclic aromatic hydrocarbons: Source, environmental impact, effect on human health and remediation," Egyptian Journal of petroleum, vol. 25, pp. 107-123, 2016.

[3] S. H. Chang, M. Y. Hsieh, H. J. Yang, M. C. Chen, C. Y. Kuo, "Effects of Diesel Vehicle Emissions of Polycyclic Aromatic Hydrocarbons on the Surrounding Environment and Residents," Journal of Environmental Science and Health, Part C: Environmental Carcinogenesis and Ecotoxicology Reviews, vol. 27, no. 3, pp. 141-154, 2009.

[4] H. Cheng, Z. Deng, P. Chakraborty, D. Liu, Y. Xu, C. Luo, G. Zhang, J. Li, R. Zhang, "A comparison study of atmospheric polycyclic aromatic hydrocarbons in three Indian cities using PUF disk passive air samplers," Atmospheric Environment, vol. 73, pp. 16-21, 2013.

[5] A. Katsoyiannis and K. Breivik, "Model-based evaluation of the use of polycyclic aromatic hydrocarbons molecular diagnostic ratios as a source identification tool," Environmental Pollution, vol. 184, pp. 488-494, 2014.

[6] G. Safo-Adu, F. G. Ofosu, D. Carboo, Y. S. Armah, "Health risk assessment of exposure to particulate polycyclic aromatic hydrocarbons at a Tollbooth on a Major Highway," American Journal of Scientific and Industrial Research, vol. 5, no. 4, pp. 110-119, 2014.

[7] B. J. Finlayson-Pitts and J. N. Pitts, Jr., "Chemistry of upper and lower atmosphere: theory, experiments and applications," San Diego: Academic, 2000.

[8] C. Bosetti, P. Boffetta, C. La Vecchia, "Occupational exposures to polycyclic aromatic hydrocarbons, and respiratory and urinary tract cancers: a quantitative review to 2005," Annals of Oncology, vol. 18, pp. 431-446, 2007.

[9] L. Gaspari, S. S. Chang, R. M. Santella, S. Garte, P. Pedotti, E. Taioli, "Polycyclic aromatic hydrocarbon DNA adducts in human sperm as marker of DNA damage and infertility," Mutation Research, vol. 535, pp. 155-160, 2003.

[10] X. Ding, X. M. Wang, Z. O. Xie, C. H. Xiang, B. X. Mai, L. G. Sun, M. Zheng, G. Y. Sheng, J. M. Fu, U. Poschl, "Atmospheric polycyclic aromatic hydrocarbons observed over the North Pacific Ocean and the Arctic area: spatial distribution and source identification," Atmospheric Environment, vol. 41, pp. 2061-2072, 2007.

[11] J. Klanova, J. Kohoutek, L. Hamplova, P. Urbanova, I. Holoubek, "Passive air sampler as a tool for long-term air pollution monitoring: Part 1. Performance assessment for seasonal and spatial variations," Environmental Pollution, vol. 144, pp. 393-405, 2006.

[12] J. Klanova, P. Eupr, J. Kohoutek, T. Harner, "Assessing the influence of meteorological parameters on the performance of polyurethane foam-based passive air samplers," Environmental Science and Technology, vol. 42, pp. 550-555, 2008.

[13] S. Yenisoy-Karakas and G. S. Tuncel, "Source Apportionment of Atmospheric Trace Element Deposition," Environmental Engineering Science, vol. 25, no. 9, pp. 1263-1272, 2008. 
[14] F. M. Jaward, N. J. Farrar, T. Harner, A. J. Sweetman, K. C. Jones, "Passive air sampling of polycyclic aromatic hydrocarbons and polychlorinated naphthalenes across Europe," Environmental Toxicology and Chemistry, vol. 23, pp. 1355-1364, 2004.

[15] I. Holoubek, A. Ansorgová, J. Kohoutek, P. Korínek, I. Holoubková, "The regional background monitoring of POPs (PAHs, PCBs, OCPs) in the Czech Republic," Organohalogen Compounds, vol. 46, pp. 387-390, 2000.

[16] S. D. Choi, C. Shunthirasingham, G. L. Daly, H. Xiao, Y. D. Lei, F. Wania, "Levels of polycyclic aromatic hydrocarbons in Canadian mountain air and soil are controlled by proximity to roads," Environmental Pollution, vol. 157, pp. 3199-3206, 2009.

[17] J. O. Grimalt, P. Fernandez, L. Berdie, R. M. Vilanova, J. Catalan, R. Psenner, R. Hofer, P.G. Appleby, B.O. Rosseland, L. Lien, J. C. Massabuau, R. W. Battarbee, "Selective trapping of organochlorine compounds in mountain lakes of temperate areas," Environmental Science and Technology, vol. 35, pp. 2690-2697, 2001.

[18] J. M. Blais, D. W. Schindler, D. C. G. Muir, L. E. Kimpe, D. B. Donald, B. Rosenberg, "Accumulation of persistent organochlorine compounds in mountains of western Canada," Nature, vol. 395, pp. 585-588, 1998.

[19] L. W. Levy, "Novel Diagnostic Tools to Detect and Monitor Persistent Organic Pollutants in Remote Mountainous Areas," Ph.D. dissertation, Department of Ecological Chemistry and Environmental Analysis, Technical University of Munich, 2008.

[20] J. Kohoutek, I. Holoubek, J. Klanova, "Methodology of Passive Sampling," TOCOEN, s.r.o. Brno/ RECETOX MU Brno. TOCOEN Report no. 300, February 2006, pp. 14.

[21] R. Mohanraj, S. Dhanakumar, G. Solaraj, "Polycyclic aromatic hydrocarbons bound to PM2.5 in urban Coimbatore, India with emphasis on source apportionment," Scientific World Journal, pp. 1-8, 2012.

[22] I. C. Lai, C. L. Lee, K. Y. Zeng, H. C. Huang, "Seasonal variation of atmospheric polycyclic aromatic hydrocarbons along the Kaohsiung coast," Journal of Environmental Management, vol. 92, no. 8, pp. 2029-2037, 2011.

[23] J. H. Seinfeld and S. N. Pandis, Atmospheric chemistry and physics: from air pollution to climate change. New York: Wiley, 2006.

[24] S. Sarkar and P. Khillare, "Profile of PAHs in the inhalable particulate fraction: source apportionment and associated health risks in a tropical megacity," Environmental Monitoring and Assessment, vol. 186, no. 5, pp. 2907-2923, 2014.

[25] S. S. Park, Y. J. Kim, C. H. Kang, "Atmospheric polycyclic aromatic hydrocarbons in Seoul, Korea," Atmospheric Environment, vol. 36, pp. 2917-2924, 2002.

[26] L. Tuduri, T. Harner, H. Hung, "Polyurethane foam (PUF) disks passive air samplers: Wind effect on sampling rates," Environmental Pollution, vol. 144, pp. 377-383, 2006.

[27] K. Nikolaou, P. Masclet, H. G. Mouvier, "Sources and chemical reactivity of polynuclear aromatic hydrocarbons in the atmosphere-A critical review," Science of the Total Environment, vol. 32, pp.103-132, 1984.

[28] M. Tobiszewski and J. Namiesnik, "PAH diagnostic ratios for the identification of pollution emission sources," Environmental Pollution, vol. 162, pp. 110-119, 2012.

[29] M. Akyüz and H. Çabuk, "Gas-particle partitioning and seasonal variation of polycyclic aromatic hydrocarbons in the atmosphere of Zonguldak, Turkey," Science of the Total Environment, vol. 408, pp. 5550-5558, 2010.

[30] C. Alves, C. Pio, A. Carvalho, C. Santos, "Atmospheric carbonaceous aerosols over grasslands of central Europe and a Boreal forest," Chemosphere, vol. 63, pp. 153-164, 2006.

[31] W. Esteve, H. Budzinski, E. Villenave, "Relative rate constants for the heterogeneous reactions of $\mathrm{NO}_{2}$ and $\mathrm{OH}$ radicals with polycyclic aromatic hydrocarbons adsorbed on carbonaceous particles. Part 2: PAHs adsorbed on diesel particulate exhaust SRM 1650a," Atmospheric Environment, vol. 40, pp. 201-211, 2006.

[32] A. Katsoyiannis, A. J. Sweetman, K. C. Jones, "PAH molecular diagnostic ratios applied to atmospheric sources: a critical evaluation using two decades of source inventory and air concentration data from the UK," Environmental Science and Technology, vol. 45, no. 20, pp. 8897-8906, 2011.

[33] P. Zhang, and Y. Chen, "Polycyclic Aromatic hydrocarbons contamination in surface soil of china: A review," Science of the Total Environment, vol. 605- 606, pp.1011-1020, 2017. 
[34] M. B. Yunker, R. W. Macdonald, R. Vingarzan, R. H. Mitchell, D. Goyette, S. Sylvestre, "Polycyclic Aromatic hydrocarbons in the Fraser River basin: a critical appraisal of PAH ratios as indicators of PAH source and composition," Organic Geochemistry, vol. 33, pp. 489-515, 2002.

[35] C. Venkataraman, J. M. Lyons, S. K. Friedlander, "Size distributions of polycyclic aromatic hydrocarbons and elemental carbon. 1. Sampling, measurement methods, and source characterization," Environment Science and Technology, vol. 28, pp. 555-562, 1994. 